\title{
Social Media and Child Welfare: Policy, Training, and the Risks and Benefits From the Administrator's Perspective
}

\author{
Tonia C. Stott \\ Ann MacEachron \\ Nora Gustavsson $\dagger$
}

\begin{abstract}
The field of public child welfare faces special challenges as it interweaves the use of social media into practice. Social media can assist agencies in meeting demands of practice such as communication, preservation of important family connections, identification of kin, and service coordination with caretakers and community partners. It also presents risks with respect to privacy, confidentiality, and safety. To look at the role of social media in child welfare practice, we began by examining the literature on social media use and how agencies are responding to the risks and benefits of this technology. We then report the findings from an exploratory national survey of training administrators $(n=14)$ that suggests states vary in both policy development and training with respect to social media in child welfare work. We further report on state training administrators' views of the perceived risks vs. benefits of the use of social media in various case management tasks and in enhancing the well-being of youth in out-of-home care. Agencies would reduce their liability risks and at the same time benefit their staff and clients by developing policies that offer guidelines to protect agency and staff privacy and safety, as well as client privacy and safety. Agencies may also promote the well-being of youth in out-of-home care by providing adequate information to staff and care-givers regarding the safe use of social media to create and maintain appropriate connections.
\end{abstract}

Keywords: Foster care; social media; technology; case management

Social media and other digitally-based technologies are increasingly becoming commonplace platforms for both communication and connection. In the field of public child welfare, social media can pose a complex mix of risks and benefits. Its benefits include expediting such case management tasks as client contact and communication, keeping children and youth connected to siblings and family, mining for potential family and relative connections for children in out-of-home care, finding missing parents and/or runaway youth, and coordination among care-givers. Despite its many potential uses in supporting case management tasks, social media also has risks that include breached confidentiality, invasion of privacy, and inadequate protection of child, family, and worker information. Yet, there is little information in the empirical literature about either the employment of social media in public child welfare or its ethical, effective, and safe use. We undertook an exploratory study of state child welfare training administrators to examine the use, policy context, staff training, and perceived risks and benefits of social media in public child welfare.

\footnotetext{
Tonia Stott, PhD, MSW, is the Coordinator for the BSW Child Welfare Education Program in the School of Social Work at Arizona State University, 411 N. Central Ave., Ste. \#800, Phoenix, AZ 85004. Ann MacEachron, PhD, MSW, is a Professor at the School of Social Work at Arizona State University. Nora Gustavsson († deceased), PhD, MSW, was an Associate Professor at the School of Social Work at Arizona State University. 


\section{Literature Review}

\section{Social Media Use in Human Services}

The helping professions have begun to give increased attention to how digital technology can be used to support and enhance client well-being (Denby-Brinson, Gomez, \& Alford, 2015). The fields of nursing, public health, and medicine have not only recognized the challenges of social media use in health care but have also begun capitalizing upon the potential assets inherent in those communication platforms. Various health care organizations have developed programs to incorporate social media in their efforts to support patients. These organizations have been using social media to work with health issues such as diabetes, obesity, smoking cessation, and medication compliance (Hall, Cole-Lewis, \& Bernhardt, 2015). The mental health field has also capitalized on people's increased use of electronic communication and social networking. Cognitive behavioral therapy appears to be well-suited for adaptation in e-mental health (Musiat \& Tarrier, 2014). Furthermore, social media has been used in the treatment of substance abuse, anxiety, and mood disorders (Berman, Wennberg \& Sinadinovic, 2015; Mewton, Wong, \& Andrews, 2012; Newby, Mewton, Williams, \& Andrews, 2014; Parikh \& Huniewicz, 2015).

Organizations serving youth have recognized the pervasive use of social media among the populations they serve, and many have responded by using these technologies while trying to minimize the risks associated with the use of social media (Schwartz et al., 2014). Populations that present particular engagement challenges, such as homeless youth, use social media to communicate with service providers, kin, employers, and friends (Rice \& Barman-Adhikari, 2014). Organizations concerned with youth mental health are using social media for prevention programming (Clark, Kuosmanen, \& Barry, 2015). Software programs have been developed in child welfare to facilitate communication and information exchange between case managers and care providers (Dodsworth et al., 2013). Real-time video technologies such as Skype and Facetime have been used to support visitation between children and parents (Quinn, Sage, \& Tunseth, 2015). The use of the internet in various aspects of service delivery can extend the availability of services and help clients avoid the stigma associated with going to an agency (Ramsey \& Montgomery, 2014). Social work as a field, however, has approached social media with caution (Baker, Warburton, Hodgkin, \& Pascal, 2014).

\section{Social Media in Child Welfare Practice}

The use of social media in child welfare has been a topic of on-going discussion in practice publications (e.g., Center for Advanced Studies in Child Welfare, 2011), and at child welfare conferences, the Children's Bureau (e.g., Smith \& Fitch, 2012), and the National Resource Center for Child Welfare and Technology (2012). Three studies have been published in the empirical literature documenting that front-line workers are using social media in their child welfare work (Breyette \& Hill, 2015; McRoy, 2010; Sage \& Sage, 2016). However, there is little in the empirical literature that addresses the extent of policy development around social media in professional child welfare, training available 
to staff from the training administrator's perspective, or the risks and benefits of the use of social media from administrators' perspectives.

Sage and Sage (2016) used a snowball sampling technique of child welfare workers across several states to explore how they engaged in social media. Most child welfare workers in their study reported using social media in their work but also reported challenges as well as benefits of its use (Sage \& Sage, 2016). The literature in allied professions also suggests multiple ways social media may be integrated into professional practice. Friend lists of youth and their parents can be mined to identify kin and natural mentors who could provide connections to children and youth in out-of-home care and to communicate with people who could be potential permanency options. When a parent's whereabouts are unknown or a youth runs away, social media postings can provide clues to their location and an avenue for communication. When parents are transient, or their phone numbers frequently change, social media may prove to be a more reliable way than traditional phone contact of staying in touch with them and communicating about appointments. Finally, for parents or kin who do not have phones, but can access the internet through friends' phones or public venues (e.g., libraries), they may be more responsive to social media site messages from child welfare staff than other forms of communication.

Most notably, social media can be integrated into child welfare practice with respect to work with youth. Youth in out-of-home care are highly vulnerable to becoming disconnected, socially and emotionally, due both to their removal from their original friendship and natural belonging groups and the continual disruption of their friendships and connections through placement instability. A potential advantage of social media use by youth in out-of-home care is that they can remain connected to friends and networks or groups of others who share their experiences. A recent study of smartphone use by foster youth reported the technology was viewed as important and helpful by the youth (Denby, Gomez, \& Alford, 2016). Smartphones can also serve to support youth empowerment by giving them a voice in their service planning in addition to facilitating emotional connections (Denby-Brinson et al., 2015). These connections could be significant sources of resilience and emotional and social development (Amichai-Hamburger, 2013; Best, Manktelow, \& Taylor, 2014; Fitton, Ahmedami, Harold, \& Shifflet, 2013). Providing youth with access to internet technologies can also increase their e-literacy and reduce the digital divide they may otherwise experience in their transition to young adulthood.

\section{Concerns about the Use of Social Media in Social Service Delivery}

Concerns about social media use in social services have focused on access to the technology, confidentiality, privacy, boundaries, informed consent, documentation, and practitioner competence in the use of the technology (Dombo, Kays, \& Weller, 2014). A 2012 study by the National Association of State Chief Information Officers (NASCIO, 2013) found that all reporting states use social media and rated the future use of social media as essential. However, only half of the states had policies and procedures to guide the use of social media to meet job responsibilities. These policies typically provided for "confidentiality, ethical conduct, security and privacy, personal use, public commenting, and transparency" (p. 2). 
The context of public services to children, youth, and families often demands additional but unique policy requirements. An initial recognition of this need occurred about ten years ago when the National Association of Social Workers (NASW, 2005) developed Standards for Technology and Social Work Practice. The standards represent an attempt to deal with the multiple challenges of the ever-increasing complexity and availability of social media as understood at that time. Recently, NASW and three other nationally-based social work organizations drafted standards for the use of technology in social work practice (Association of Social Work Boards International Technology Task Force, 2015). These standards are expected to be published by early 2017. It is unclear how well schools of social work are preparing practitioners for the digital component of contemporary practice (Young, 2015).

Clear guidance on how to use social media with clients is thus still evolving. For example, clients may request to have an online relationship through social networking sites such as LinkedIn or Facebook and may want to use text and email to communicate with their social worker. These common practices can present ethical challenges (Reamer, 2015). For example, it is unclear how social workers should respond to friend requests from clients. Boundaries can be further tested by texting (DeJong \& Gorrindo, 2014). Texting can be used multiple times a day, every day. The mixing of personal and professional social media is another area of risk (Kimball \& Kim, 2013). Guidelines on when and how to use social media to seek information on clients who may not have consented to such searches are still in development. Furthermore, practitioners may not realize how their searches of clients can make their social media profiles or account names visible to those clients through anti-cyber stalking programs.

In child welfare, specifically, social media can pose multiple dilemmas. Millennials, Generation $\mathrm{Z}$ youth, and young adults may be more comfortable communicating via text message than through the phone. Thus, the most efficient method of communicating with young parents may be lost to child welfare staff who are not comfortable using text messages or do not have a business line that is text-compatible. Concerns for child safety can also be amplified. Out-of-home care providers and case managers who do not understand social media, or the ease with which pseudonym accounts can be created, may miss opportunities to have discussions with youth about their social networking and safety online. Even youth who do not have access to the internet at their placements can be communicating with family and others on their social media accounts through public computers or the smartphones of peers at school. Children and youth may unwittingly reveal their address or school name on social media sites or even post pictures with GPS coordinates embedded in them, revealing their location to dangerous parents or others who are barred from contact with them. Additionally, foster youth may be especially vulnerable to child predators and traffickers who use social media sites to look for disconnected and desperate youth.

Mining parents' friend lists for kin and viewing information posted on social media sites can also pose ethical and legal dilemmas in child welfare. It is unclear how information procured through a search of a parent's social media site can be used in dependency hearings or the assessment of safety. Researchers continue to try to understand how social media can be used to benefit which clients with what types of challenges. The 
unanswered questions on effectiveness can lead to reluctance to embrace the technology (Harris \& Birnbaum, 2015). However, social media is omnipresent and has become a component of contemporary practice (Mishna, Bogo, Root, \& Fantus, 2014).

The ubiquity of social media suggests that child welfare agencies must negotiate the use of social media if only because child welfare staff, families, care providers, and youth may use it even without input, guidance, or direction from the organization. The professionally appropriate, safe, and ethical use of this technology is necessary, both to manage the risks social media poses and simultaneously offer templates for practice in environments saturated by social media and technological innovation.

It is in this context that we undertook an exploratory study of training administrators of state child welfare agencies to examine whether public child welfare agencies: a) are using social media in practice, b) are guided by policies regarding the use of social media in child welfare, and c) provide staff training to promote competence in appropriate, safe, and ethical use of social media technology. We also explored how training administrators view the balance of risks versus benefits of social media use by child welfare workers and youth to meet child welfare goals.

\section{Methods}

\section{Participants}

Internet searches were performed to garner the name of the state-level department or division responsible for child welfare in each state. Further searches were performed to attempt to ascertain email addresses or general phone numbers for the state-wide training departments in each state. If email addresses were not publicly available, phone calls were made to inquire about the person and/or specific agency responsible for the oversight of state-wide training and the email addresses of contact people. Further searches and inquiries were conducted until names and email addresses of state-wide administrators, directors, and/or managers were collected. An email was sent to the identified person in all 50 states describing the purpose of the survey and asking if she/he would be the person most suitable to respond to a survey about the extent to which training was available to the child welfare workforce in that state on the subject of social media. Correspondence including both phone calls and emails continued until all means were exhausted to identify state-wide training administrators, directors, and/or managers or their nominated representatives along with a confirmed email address for each state. These iterative search processes were used to ensure that our survey targeted state-level personnel involved in state-wide training or its oversight. Although a number of states use counties to manage and train for child welfare work, state-level administrators receive and manage federal child welfare funds.

From among the 50 states, we identified 49 people with a confirmed email address who had a role as a state-level training administrator, or as a director, manager, contracted provider, university partner, or a nominated representative of the state level training administrator. We sent an invitation by email to these 49 training representatives to participate in our electronic survey. Data collection took place from August 2014 through 
December 2014. The survey included an option for the participants to provide link(s) to their state or county policies relevant to social media use in child welfare and/or to provide additional information about procedures and protocols concerning social media. From among the 49 potential respondents, 17 responses were received; however, 3 responses were entirely blank. The response rate was $28 \%(\mathrm{n}=14)$. Of these, 2 participants provided state-level links to their policies. The research protocol was approved by the IRB and permission to proceed was authorized.

\section{Measures}

Training administrators or their designees responded to an on-line Qualtrics survey. The survey questions aimed to assess the extent to which child welfare staff were using social media for work-related purposes and the extent to which policy was in effect concerning the professional use of social media. Survey items further assessed the extent to which staff participated in training about social media in child welfare work across three case management topic areas, namely: a) searching for clients on the internet or communicating with clients through social media, b) privacy and protection of staff, and c) talking with youth in out-of-home care about their use of social media. If trainings were offered, participants were asked to identify the typical content of each training area.

Additionally, the relative risks and benefits of using the internet and social media was assessed by child welfare administrators on a 10-point scale ranging from: 1 to 3 (extremely risky with minimal benefits), 4 to 7 (moderate benefits with moderate risks), and 8 to 10 (extremely beneficial with minimum risks). One area of interest was the perceived risk/benefits of child welfare staff using social media to search for missing children, extended family and fictive kin, and parents. A second area of interest was the risk/benefits of child welfare staff using social media to communicate with youth in out-of-home care, parents, extended family and fictive kin, and out-of-home care providers. A third area was the perceived risks/benefits of youth in out-of-home-care using the internet and social media to search for their family and friends, communicate with family and friends, and search for educational resources, jobs, and health information.

\section{Analysis}

We employed univariate descriptive statistics. The number/percent of respondents as well as means and standard deviations are shown in Tables 1 and 2. The small sample size limited further analysis.

\section{Results}

\section{Use of Social Media and Policy Development}

Our initial research question was whether public child welfare agencies and staff use social media in their work, and specifically, in the case management areas of searching for and communicating with clients. As shown in Table 1, $10(71 \%)$ of the 14 training administrators in our sample indicated that their agencies allow child welfare staff to use social media to search for missing children, missing parents, or family members in the 
friend lists of their clients. Half $(50 \%)$ of the training administrators reported that their agencies allow child welfare staff to use social media to communicate with family and friends of children and youth in out-of-home care. Thus, the majority of the reporting states use social media to search for and communicate with their clients.

Table 1. Social Media Use, Policy Development, and Child Welfare Staff Training $(n=14)$

\begin{tabular}{lc}
\hline & $\mathbf{n}(\mathbf{\%})$ \\
\hline $\begin{array}{l}\text { Agency allows use of internet and social media for: } \\
\text { Searching for missing children, for missing parents or for family members in } \\
\text { "friend" lists of children or parents }\end{array}$ & $10(71 \%)$ \\
$\begin{array}{l}\text { Communicating with family/connections of children and youth in out-of-home } \\
\text { care }\end{array}$ & $7(50 \%)$ \\
$\begin{array}{l}\text { There is agency policy about the use of the internet and social media in child } \\
\text { welfare work: }\end{array}$ & \\
$\quad$ No, no policy & $5(36 \%)$ \\
$\quad$ No, but we are developing a policy & $6(43 \%)$ \\
$\quad \begin{array}{l}\text { Yes, some specific policies } \\
\text { Yes, a comprehensive policy }\end{array}$ & $3(21 \%)$ \\
Training topic areas covered: & $0(0 \%)$ \\
$\quad \begin{array}{l}\text { Searching for clients and/or communicating with clients through social media } \\
\text { Privacy and protection of personal internet and social media accounts }\end{array}$ & $9(64 \%)$ \\
Talking with youth in out-of-home care about social media & $8(57 \%)$ \\
\hline
\end{tabular}

A related research question was whether there was agency policy on child welfare staff's use of social media for case management duties. Only 3 states (21\%) reported having at least one specific policy while no state reported having a comprehensive policy in place. One of these states emphasized the official use of social networking and social media for public education regarding the agency's mission, official interaction with the public, connection with agencies and public "in times of crisis," and/or to "assist with emergency, disaster, or crisis communications" (Oklahoma Department of Human Services, N.D.). This state also included a link to the ethics and expected code of conduct for using official social networking and social media.

In another state, while there was no official section in their policy manual that addressed the use of social media by staff, a directive was sent via email to staff stating that social media could be used only with agency permission and in accordance with the following parameters: a) the social media account had to be separate from the staff person's personal account, b) the account had to reflect the professional identity of the worker, c) the email address associated with the account could not be the staff member's state or personal email address, and d) they could not reveal confidential information through social media communication. This approach offers guidelines regarding the access and use of technology for social media in social work practice, though the guidelines are not set forth in official policy. In the policy manual for this state, the term "social media" appears once. In the section on identifying family and connections for older youth with a case plan goal of APPLA (Another Planned Permanent Living Arrangement), the policy states that there should be documented efforts to find family including through the use of search technologies and social media. This approach seems to recognize a benefit of using social 
media in child welfare work, though standards for ethical conduct in carrying out social media searches were not simultaneously addressed.

Despite the examples of these two states, the majority of responding states reported having no policy ( 5 or $36 \%$ ) or being in the process of developing policy ( 6 or $43 \%$ ). These results suggest that policy development is loosely tied, at this time period, to the use of social media in accomplishing child welfare case management search and communication tasks.

\section{Training}

The third research question explored whether agencies provide staff training regarding the use of social media to accomplish child welfare case management tasks, and if so, to identify incorporated topics. Nine (64\%) states provide agency-based trainings. This is consistent with the previous finding that the majority of responding states employ social media in child welfare case management with clients.

The training content that these nine states are most likely to incorporate includes searching for client information online and online communication with clients. Featured topics were the ethics of searching for personal information about clients and how information gleaned from social media accounts can be used in child welfare decisionmaking. The next most likely topics were the circumstances under which staff can communicate with clients via social media (e.g., only in emergency circumstances like an abducted or runaway child) and how staff are to represent themselves when communicating with clients or the families of clients through social media (e.g., does the worker's professional profile need to make it apparent that the person represents a child welfare organization).

Eight (57\%) states incorporate training content about the privacy and protection of staff members' personal accounts. The most likely topics included were importance and/or meaning of password protections, privacy settings, guidelines on posting pictures, and how to respond to client requests to friend or follow them. Only 2 states mentioned inclusion of information on how to respond to cyber-stalking or cyber-harassment from clients or colleagues.

With respect to training content about talking with youth in out-of-home care about their social media use, only 4 (29\%) of the responding states provide training on this topic. These states were most likely to focus on the importance of talking with youth about safety issues related to posting pictures online and about who is on the youth's friend lists.

\section{Risks vs. Benefits of Social Media}

The last survey question asked training administrators their opinion about the risks versus benefits of: a) child welfare workers using social media to engage in case management activities related to the permanency and well-being of children, and b) of youth in out-of-care using social media. As shown in Table 2, training administrators believe that more benefits than risks exist in both realms 
Table 2. Perceived Risk/Benefit of Using Social Media in Child Welfare Work

\begin{tabular}{lcc}
\hline Child Welfare Workers' Use of Social Media & Mean (SD) & $\begin{array}{c}\text { Range of } \\
\text { Scores }\end{array}$ \\
\hline To search for: & $8.1(1.8)$ & $5-10$ \\
$\quad$ Missing children & $6.3(2.1)$ & $4-10$ \\
$\quad$ Extended family/fictive kin & $6.1(2.2)$ & $2-9$ \\
$\quad$ Parents & & \\
To communicate with: & $8.1(1.8)$ & $5-10$ \\
$\quad$ Youth in out-of-home care & $7.2(1.9)$ & $5-10$ \\
$\quad$ Parents & $6.4(2.4)$ & $2-9$ \\
$\quad$ Extended family/fictive kin & $5.9(2.9)$ & $2-10$ \\
$\quad$ Out-of-home care providers & $7.7(2)$ & $5-10$ \\
Foster care youths' use to search for: & $7.6(1.5)$ & $5-10$ \\
$\quad$ Educational resources/programs & $6.6(1.9)$ & $4-10$ \\
$\quad$ Jobs & $5.5(0.9)$ & $4-7$ \\
$\quad$ Health information & $5.5(2.2)$ & $2-10$ \\
$\quad$ Family & & \\
$\quad$ Friends from their past & $5.9(1.2)$ & $4-8$ \\
Foster care youths' use to communicate with: & $5.8(1.5)$ \\
$\quad$ Family & $3-8$ \\
$\quad$ Friends & \\
\hline Note. $\mathrm{n}=14$. The risk benefit scale ranges from 1 (extremely risky with minimal \\
benefits) to 10 (extremely beneficial with minimum risks). Low benefit/high risk \\
scores range from 1 to 3, moderate benefit and risk scores range from 4 to 7, \\
and high benefit and low risk scores range from 8 to 10. \\
\hline
\end{tabular}

In the child welfare task of searching for child and family information, the greatest perceived benefit versus risk was for finding missing children, followed by the more moderate benefit of finding missing parents or extended family. In the child welfare task of communication, the greatest benefit versus risk was for communicating with children in out-of-home care, followed by the more moderate benefit of communicating with parents, extended family, and out-of-home care providers.

In the realm of out-of-home youth using the internet and social media, the greatest but still moderately perceived benefit versus risk related to youth searching for information about educational resources, jobs, and health. Other moderate perceived benefits were for youth to find and communicate with family and friends.

\section{Discussion}

The results of this study indicate that of the states participating in the survey, most allow child welfare workers to use social media in their work and that respondents believed, overall, that the benefits of social media use by staff outweigh the risks. However, a limited number of states who responded to the survey have policies concerning social media use in child welfare. Furthermore, few respondents noted providing training on how child welfare professionals can protect themselves when searching for and communicating with clients through social media, ethically search for client information, safely and ethically communicate with clients, or the importance of talking with older children and youth about 
their social media posts, tags, and discussions. These state-level results are congruent with the Sage and Sage study (2016) where workers in three states reported being unlikely to have practice and/or case management guidance in the use of social media by either clear agency policy or through agency training. Given the ubiquity of individual smartphones, the ease of access to social media by staff and clients, and the rapidity of change in digital technology, states may be reluctant to develop specific policies for worker use of social media in favor of more universal concerns for the ethical and safe use of social media through employee training.

The primary limitations of this study are two-fold: the small sample size of the statelevel training administrators and an unknown generalizability of results. Although the sample size was small, the response rate of $28 \%$ is not atypical of online surveys (Nulty, 2008; Pedersen \& Nielsen, 2016). Given the paucity of literature on the subject of social media in child welfare work, these initial results serve not as generalizable population parameters but rather as an important genesis for discussions of this developing topic at the macro level of child welfare policy and training. Our ongoing research involves phone interviews with state-level administrators to deepen the understanding of the barriers to policy development and training related to social media use at both the state level and, where applicable, at the county level. Secondly, we plan to use Skype to conduct focus groups about the challenges in policy development and training for case management uses of social media.

\section{Implications}

Social media use in child welfare work has risks, and there are risks to older children and youth accessing the internet and having social media accounts. There are also considerable benefits. The risks can be reduced by some degree with training, open discussion, and information-sharing. There is a gap, however, between acceptance of risks in the use of social media in public child welfare and the congruent policy and staff training offered to ensure practitioner competence in engaging online ethically, safely, and confidentially. Sage and Sage (2016) suggest that agencies provide guidance on the ethical use of social media. Social media use, as revealed in this study, provides an example of how realities on the ground can result in practices before formal comprehensive policies are developed. On a daily basis, child welfare staff deal with the pervasiveness of social media in the lives of their clients. Their own use of social media is often added to the mix.

Guidelines on how staff should respond to these realities may be developed on a caseby-case, idiosyncratic basis such that practice precedes policy. Agencies would reduce their liability risks and benefit their staff and clients by developing policies that offer guidelines to protect agency and staff privacy and safety, as well as client privacy and safety. The NASCIO report (2013) strongly recommends that state governments develop such "comprehensive social media participation policies" (p. 4) and offers a checklist of issues to include. The 2005 National Association of Social Workers' and the 2015 Association of Social Work Board's publications on professional practice standards include helpful checklists and highlight important principles to guide policy development in the use of social media technologies. An appropriate starting point for the development of these guidelines is an understanding of the risks and benefits, the capability of the technology to 
be misused and misunderstood, and the involvement of the many stakeholders in child welfare. Care providers, attorneys, juvenile courts, service providers, and case managers have a vested interest in the technology. However, foster children and youth may have the most to gain or lose by being denied or poorly prepared for the effective and safe use of this essential technology.

\section{References}

Amichai-Hamburger, Y. (2013). Youth internet and well-being. Computers in Human Behavior, 29, 1-2. doi:https://doi.org/10.1016/j.chb.2012.05.023

ASWB International Technology Task Force. (2015). Model regulatory standards for technology and social work practice. Culpeper, VA.: Association of Social Work Boards. Retrieved from https://www.aswb.org/wp-content/uploads/2015/03/ASWBModel-Regulatory-Standards-for-Technology-and-Social-Work-Practice.pdf

Baker, S., Warburton, J., Hodgkin, S., \& Pascal, J. (2014). Reimagining the relationship between social work and information communication technology in the network society. Australian Social Work, 67, 467-478. doi:https://doi.org/10.1080/0312407X.2014.928336

Berman, A., Wennberg, P., \& Sinadinovic, K. (2015). Changes in mental and physical well-being among problematic alcohol and drug users in 12-month internet-based intervention trails. Psychology of Addictive Behaviors, 29 (1), 97-105. doi:https://doi.org/10.1037/a0038420

Best, P., Manktelow, R., \& Taylor, B. (2014). Online communication, social media and adolescent well-being: A systematic narrative review. Children and Youth Services Review, 41, 27-36. doi:https://doi.org/10.1016/j.childyouth.2014.03.001

Breyette, S. K., \& Hill, K. (2015). The impact of electronic communication and social media on child welfare practice. Journal of Technology in Human Services, 33(4), 283-303. doi:http://doi.org/10.1080/15228835.2015.1101408

Center for Advanced Studies in Child Welfare (2011). CW $360^{\circ}$ Child Welfare and Technology, Spring. University of Minnesota: School of Social Work. Retrieved from: http://cascw.umn.edu/wp-content/uploads/2013/12/CW360_2011.pdf

Clark, A., Kuosmanen, T., \& Barry, M. (2015). A systematic review of online youth mental health promotion and prevention interventions. Journal of Youth \& Adolescence, 44, 90-113. doi:https://doi.org/10.1007/s10964-014-0165-0

Denby-Brinson, R., Gomez, I., \& Alford, K. (2015). Becoming 'SMART' about relationship building: Foster care youth and the use of technology. Issue Brief Social Services, 3, 1-12.

Denby, R., Gomez, E., \& Alford, K, (2016). Promoting well-being through relationship building: The role of Smartphone technology in foster care. Journal of Technology in Human Services, 34, 183-208. doi:https://doi.org/10.1080/15228835.2016.1168761 
DeJong, S., \& Gorrindo, T. (2014). To text or not to text: Applying clinical and professionalism principles to decisions about text messaging with patients. Journal of the American Academy of Child \& Adolescent Psychiatry, 53, 713-715. doi:https://doi.org/10.1016/j.jaac.2014.05.002

Dodsworth, J., Bailey, S., Schofielf, G., Cooper, N., Fleming, P., \& Young, J. (2013). Internet technology: An empowering or alienating tool for communication between foster-carers and social workers? British Journal of Social Work, 43, 775-795. doi:https://doi.org/10.1093/bjsw/bcs007

Dombo, E., Kays, L., \& Weller, K. (2014). Clinical social work practice and technology: Personal, practical, regulatory, and ethical considerations for the twenty-first century. Social Work in Health Care, 53, 900-919. doi:https://doi.org/10.1080/00981389.2014.948585

Fitton, V., Ahmedani, B., Harold, R., \& Shifflet, E. (2013). The role of technology on young adolescent development: Implications for policy, research and practice. Child \& Adolescent Social Work Journal, 30, 399-413. doi:https://doi.org/10.1007/s10560$\underline{013-0296-2}$

Hall, A., Cole-Lewis, H., \& Bernhardt, J. (2015). Mobile text messaging for health: A systematic review of the reviews. Annual Review of Public Health, 36, 393-415. doi:https://doi.org/10.1146/annurev-publhealth-031914-122855

Harris, B., \& Birnbaum, R. (2015). Ethical and legal implications on the use of technology in counseling. Clinical Social Work Journal, 43, 133-141. doi:https://doi.org/10.1007/s10615-014-0515-0

Kimball, E., \& Kim, J. (2013). Virtual boundaries: Ethical considerations for use of social media in social work. Social Work, 58, 185-188. doi:https://doi.org/10.1093/sw/swt005

Mewton, L., Wong, N., \& Andrews, G. (2012). The effectiveness of internet cognitive behavioral therapy for generalized anxiety disorder in clinical practice. Depression and Anxiety, 29, 843-849. doi:https://doi.org/10.1002/da.21995

McRoy, R. (2010). Do you Facebook or Twitter? Survey findings report. The University of Texas at Austin, Center for Social Work Research.

Mishna, F., Bogo, M., Root, J., \& Fantus, S. (2014). Here to stay: Cyber communication as a complement in social work practice. Families in Society, 95, 179-186. doi:https://doi.org/10.1606/1044-3894.2014.95.23

Musiat, P., \& Tarrier, N. (2014). Collateral outcomes in e-mental health: A systematic review of the evidence for added benefits of computerized cognitive behavior therapy interventions for mental health. Psychological Medicine, 44, 3137-3150. doi:https://doi.org/10.1017/S0033291714000245

National Association of Social Workers. (2005). Standards for technology and social work practice. Retrieved from: http://www.socialworkers.org/practice/standards/technology.asp 
National Resource Center for Child Welfare \& Technology. (2012). Social media for child welfare resource guide. Retrieved from

http://www.uwgb.edu/newpart/PDF/SocialMediaforChildWelfareResourceGuide\%20 8-27-2012.pdf

National Association of State Chief Information Officers. (2013). Examining state social media policies: Closing the gaps. NASCIO Issue Brief, 1-12. Retrieved from http://www.nascio.org/Publications/ArtMID/485/ArticleID/103/Examining-StateSocial-Media-Policies-Closing-the-Gaps

Newby, J., Mewton, L., Williams, A., \& Andrews, G. (2014). Effectiveness of transdiagnostic internet cognitive behavioural treatment for mixed anxiety and depression in primary care. Journal of Affective Disorders, 165, 45-52. doi:https://doi.org/10.1016/j.jad.2014.04.037

Nulty, D. (2008). The adequacy of response rates to online and paper surveys: what can be done? Assessment and Evaluation in Higher Education, 33(3), 301-314. doi:https://doi.org/10.1080/02602930701293231

Oklahoma Department of Human Services (n.d). Official Social Networking and Social Media (SNSM) business use by Oklahoma Department of Human Services (DHS) employees. Retrieved from: http://www.okdhs.org/library/policy/Pages/dhs002370013000.aspx

Parikh, S., \& Huniewicz, P. (2015). E-health: An overview of the uses of the internet: Social media, apps, and websites for mood disorders. Current Opinion in Psychiatry, 28, 13-17. doi:https://doi.org/10.1097/YCO.0000000000000123

Pedersen, M., \& Nielsen, C. (2016). Improving survey response rates in online panels: Effects of low-cost incentives and cost-free text appeal interventions. Social Science Computer Review, 34(2), 229-243. doi:https://doi.org/10.1177/0894439314563916

Quinn, A., Sage, K., \& Tunseth, P. (2015). An exploration of child welfare workers' opinions of using video-assisted visitation in the family reunification process. Journal of Technology in Human Services, 33, 5-15. doi:https://doi.org/10.1080/15228835.2014.998573

Ramsey, A., \& Montgomery, K. (2014). Technology-based interventions in social work practice: A systematic review of mental health interventions. Social Work in Health Care, 53, 883-899. doi:https://doi.org/10.1080/00981389.2014.925531

Reamer, F. (2015). Clinical social work in a digital environment: Ethical and riskmanagement challenges. Clinical Social Work Journal, 43, 120-132. doi:https://doi.org/10.1007/s10615-014-0495-0

Rice, E., \& Barman-Adhikari, A. (2014). Internet and media use as a resource among homeless youth. Journal of Computer Mediated Communication, 19, 232-247. doi:https://doi.org/10.1111/jcc4.12038

Sage, M., \& Sage, T. (2016). Social media use in child welfare practice. Advances in Social Work, 17, 93-112. doi:https://doi.org/10.18060/20880 
Schwartz, S., Rhodes, J., Liang, B., Sanchez, B., Spencer, R., Kremer, S., \& Kanchewa, S. (2014). Mentoring in the digital age: Social media use in adult-youth relationships. Children and Youth Services Review, 47, 205-213. doi:https://doi.org/10.1016/j.childyouth.2014.09.004

Smith, B., \& Fitch, D. (2012). Friending your clients on Facebook: How social media influences child welfare practice. In Children Bureau's Topical Webinars. Retrieved from https://cb100.acf.hhs.gov/downloads/FriendingYourClientsonFacebook_Transcript.p df.

Young, J. (2015). Assessing new media illiteracies in social work education: The development and validation of a comprehensive assessment instrument. Journal of Technology in Human Services, 33, 72-86. doi:https://doi.org/10.1080/15228835.2014.998577

\section{Author note:}

Address correspondence to: Tonia Stott, School of Social Work, Arizona State University, 411 N. Central Ave., Ste. \#800, Phoenix, AZ 85004, 602-496-0077, Tonia.Stott@asu.edu 